\title{
MALNUTRITION, CHILD MORBIDITY AND THE FAMILY DECISION PROCESS
}

\author{
Peter S. HELLER and William D. DRAKE* \\ International Monetary Fund, Washington, DC 20431, USA \\ University of Michigan, Ann Arbor, MI 48109, USA
}

Final version received October 1978

This paper suggests a microeconomic model of the process by which infants and toddlers are subject to malnourishment, diarrhea and other illnesses in developing countries. It is econometrically estimated in a closs-section, time-series basis for 1200 children from Candelaria, Colombia. The model focuses on four issues: (i) the impact of economic constraints and intra-family resource allocation decisions on a child's nutritional and health status, (ii) the interrelationship between malnutrition, diarrhea and other dise'ses, (iii) the impact on health and nutritional status of specifi: policy intervientions (maternal chilu health education, food supplementation and the encouragement of breast feeding), and (iv) the importance of distinguishing between the effect of different policy variables on a child's height and weight during this period.

\section{Introduction}

In many developing countries, childhood malnourishment and morbidity are among the most se:ious burdens of underdevelopment. As such, economists have begun to evaluate the cost-effectiveness of specific nutritional supplementation and health programs. ${ }^{1}$ Yet the formulation of such programs and the evaluation of their impact remains seriously limited. Most studies lack a coherent model of the forces influencing change in a child's nutritional and health status, give only limited consideration to socioeconomic variables, and lack sufficient data over time to measure empirically the impact of specific policies.

In this paper, wi: estimate an econometric model of the nutritional and health status of pre-school children. Our clata are drawn from observations on approximately 1200 children participating over a 7-year period in the Promotora maternal-child health progı am in C'andelaria, Colombia. ${ }^{2}$ Three

*The authors grateful y acknowledge the comment:s and oriticism of J. Chalmers, L. Fajardo, S. Garn, R. Held, J. Kmenta, R. Porter, A. Pradilla, K. Shapiro, G. Simmors and F. Zerfas, and the generous financial assistance of the School of Natural Resources, the Center for Reserrch on Economic Development at the University of Michigan, and the Community Systems Foundation.

${ }^{1}$ Selowsky and Reutlinger (1976).

${ }^{2}$ Promotora is the Spanish term for the nurse-volunteers who worked in the program. 
sets of issues are of central concern:

(1) How is a child's nutritional and realth status influenced by economic constraints on family and intra-family resource allocation decisions? $?^{3}$ For example, what factors determine the level of food expenditure and the decision to nurse? Is there evidence of parental discrimination between children? Is there an adverse effect of fertility on the allocation of resources to each child? Is the quality of parental care an important factor in predicting a child's nutritional or health status?

(2) Does a deterioration of a child's nutritional status increase its risk of illness or morbidity? Conversely, do diarrhea or other illnesses seriously weaken a child's nutritional status?

(3) What effect would such policy interventions as maternal-child health education, food supplementation or promotion of breast feeding have on a child's health or nutritional status?

Section 2 contains a detailed discussion of the model and its specification for economic analysis. Section 3 provides a description of the Promotora program and discusses the data used in the analysis. Section 4 discusses th econometric issues that arise in estimating the model, and section 5 examines the results and implications of the estimated model.

\section{The model}

Our model assumes that a child's nutritional and health status reflects the combined impact of basic physiological development processes, genetic factors and of economic decisions maủe by the family within the context of a given environment. The latter determines the quality and quantity of resources devoted to a child over the course of its early development. Our model is highly abstract and greatly simplifies extremely complex physiological, epidemiological and nutritional processes. Any one of the relationships implicit in the model has been the subject of substantial clinical research, and it would be impossible either to survey this research in this paper or to incorporate adequately the results of such research in our model. However, we believe that the structure of our model is not inconsistent with the basic medical literature and that the costs of simplification are outweighed by the gains from examining a more complete set of the factors influen ing a child's developnent. ${ }^{4}$

The ersence of the model is summarized in eqs. (1) and (2) below. Assume

\footnotetext{
${ }^{3}$ For examples of this view, see Holler (1976), Welch (1974), Willis (1973), and Grossman (19\%2).

${ }^{4}$ For a significant introduction to these issues, the readr is eferred to Robson (1272), Scrimshaw et al. (1968), Morley (1973), Maitorell $(1975,1976)$, and Cravioto (1976).
} 
that for any child $i$ in family $j$ at time $t$, a physiological production function (1) describes the transforme.tion of foud inputs into the child's nutritional status, $N_{i j t}$, where

$$
N_{i j t}=f\left(N_{i j t-1}, B_{i j t}, F_{i j r}, H_{i j t}\right),
$$

and where $B_{i j t}$ measures the nutrients provider through breast feeding, $H_{i j t}$ measures the child's health saatus, and $F_{i j t}$ is a vector of the quantity of other nutrient inputs. The realization of a child's natv:al propensity for physical growth in exich phase of its development is a fun tion of its past nutritional status (or birthweight, $N_{i j 0}$, for a child in the neonatal period), ${ }^{5}$ the quanitity and quality of its nutrient intake, its ability to use these resources efficiently and the level of its current bodily demand for nutrients. For an infant or toddler, the latter two factors are sritically influenced by a child's health status; for example, diarthea may limit bodily absorption of nutrients, while parasites may be an additional source of demand for nutrients. ${ }^{6}$

Particularly in developing countries, a child's health status is the joint outcome of several factors; (i) the :nedical risks inherent in the quality of its external environment $E_{i j}$; (ii) the extent to which its parents are able to insulate a child from these risks by providing non-food inputs (clothing, medical care, shelter, parental attention. etc.), $M_{i j t}$, high quality parental care, $L_{i j t}$, and adequate nutrient intake; and (iii) its own physical ability to overcome the threat of illness without significant pain or disability. A child that is well-nourished, has not experienced any sudden adverse nutritional change, and one that was healthy in the past will have greater resistance to illness. These factors are reflected in structural equation (2):

$$
H_{i j t}=g\left(N_{i j t}, M_{i j t}, H_{i j t-1}, \Delta N_{i j t}, E_{j t}, L_{i, j t}\right) .
$$

In no instance can these inputs fully insulate a child from illness. In fact, it is through exposure to disease agents and illness that a child acquires a degree of subsequent natural immunity. ${ }^{7}$ Our model only allows us to explain why some children may be excessively at risk to morbidity.

\footnotetext{
${ }^{5}$ In specifying an equation for $N_{i j 0}$, the child's weight at birth, the arguments would relate as much to the nutritional and health status of the mother and the quantity and quality of her nutrient intake. We attempted to estimate an econometric model of child birthweight from (ur sample but were precluded by the absence of precise birthweight data. The inclusion of $N_{i j t-1}$ also takes account of genetic factors.

${ }^{6}$ Similarly, episodes of fever increase the nutrient requirements for nor mal bodily development. A child's health status may also influence the level of nutrient input; in some cultures, parerts respond to the symptoms of illness by the tempo:ary withdrawal of normal food and water intake. See Scrimshaw et al. (1968).

${ }^{7}$ In fact, it is a matter of debate among tropical ;ediatricians whether it is advisable to shield the child fully from the risks of particular diseases for fear that, as a consequence, the child will never build up any natural immunity (e.g., the debate on the advisability of malaria prophylaxis).
} 
In the context of economic models of househuld behavior, ${ }^{8}$ one can imagine that a family decision process determines ihe allocation of family resources to a particular child in the form of $B_{i j t}, F_{i j t}, M_{i j t}$ and perhaps $E_{j t}$ (through migration). Parents are assumed to derive utility over their lifetime from the number and quality of surviving children as well as from their own consumption of leisure and commodities. In maximizing utility, parental choices are subject to constraints which are both internal and external to the family. Their :ornmand over resources is limited by their wealth, the market wage rate an 1 commodity prices. Parental age and knowledge of childrearing will i itfluence their efficiency in achieving a given level of child qua'ity. Parenial decisions may also be influenced by government policies. ${ }^{9}$ Such constrain's inevitably force the parents to make interpersonal judgments between themselves and their children. This may even inv'lve conscious discrimination (e.g., for working members of the household, against girls, or against higher parity children). ${ }^{10,11}$

Such models suggest that parents develop decision rules concerning the allocation of parental time and family income between activities (labor, leisure and child care) and commodities, and their allocation among members of the family. In principle, a subset of these decision rules could be specified as reduced form equations for $F_{i j t}, B_{i j t}$, and $M_{i j t}$, where a child's consumption of goods and parental time is a function of price, income, parental preferences as between children, parental quality in child-rearing and the family's size and age-struciure. Yet estimation of reduced for:n equations is not feasible, as it would require detailed data on the specific level and composition of consumption of individual children. Lacking such data, wc directly estimate structural eqs. (1) and (2), using a set of instruments to proxy the factors influencing the unknown $F_{i j t}, B_{i j t}$, ard $M_{i j t}$ vectors. The specification of these structural equations is described below.

\subsection{Nutriticnal status model}

Our choice of nutritional status indicators, $N_{i j t}$, reflects the apparent conseisus in the nutrition literature that one should differentiate the process of nutritional change inio its acute and chronic manifestations. Two complementary anthropometric measures are used: a child's weight relative to its

\footnotetext{
${ }^{8}$ See Hellier (1976) and Willis (1973.

${ }^{9}$ For example, programs in nutritional s!:pplementation and maternal-child health education may influence parental decisions; government griin pricing policies may affect both income and the cost of food.

${ }^{10}$ Most of the literature does not explicitly examine discrimination betwean family members. An exception to this is reflected in papers by Welch (1974) and Heller (1976). In the latter, it is argued that the parents' utility function includes the number of surviving children as an argument and that the probability of survival is itself parentally influenced, if not determined.

${ }^{11}$ Unintended discrinination may occur against higher parity children (s.g., if the qualit! of breast rnilk is lower in nutrient value or the attention of olde: parents is les:).
} 
height $(W T H T)$ and its height relative to its age $\left(H T A(i E) .{ }^{12}\right.$ Specifically. a child's weight, relative to the median weight for a sample of children of the same height and sex (WTHT), measures the degree of acute malnourishment associated with recent weight loss and insufficient nutrient intake and/or bodily absorption. A child's height, relative to the median height for a sample of children of the same age and sex (HTAGE), provides a measure of whet'ler a child is physically stunted ir. its structural development due to chronic nutrient deficiency. We also include the weight for age (WTAGE) standard in order to facilitate comparison with other studies. ${ }^{13}$

The economic consequences of a low score on either of these measures are not well-established in the literature. Acute malnourishment is said to place the child at higher risk of morbidity. Stunting is clearly associated with slower cellular growth in the brain. although there is no conclusive evidence about the effect of this on mental capacity or development. Some argue that the intellectually damaging consequences of malnourishment primarily arise from the attendant apathy and listlessness that preclude a normal social and intellectual responsiveness to the en ironment. ${ }^{1{ }^{14}}$ This phenomenon may be as much the consequence of a low WTHT position. It is an area where further research is clearly needed.

Three principal nutrition equations are specinied as follows:

$$
\begin{aligned}
& W_{T H T_{t k}}=N_{1}\left[\text { FOOD }_{t k}, N U R S_{t k}, W E A N L_{t}, \text { PR.SEVERE.DIAR. } \text {, }_{t k}\right. \text {, } \\
& \text { F'R.MILD.DIAR.tk, PR.SICKNESS, } \\
& {\left[F O O D^{*} P R . D I A R\right]_{t, l}, S F X_{k}, B R T H O R D,(\# C H<6) \text {, }} \\
& \text { INTVL, EDMO, EDFA, AGEFA } t^{*} \text { AGEMO, } \\
& A G E D U M_{t k}, \quad P R O M O_{t k}, \text { BSRTHCON, WTHT } T_{t-1} \text {, } \\
& \left.H T A G E_{t-1}, \varepsilon_{1}\right] \text {, } \\
& H T A G E_{t k}=N_{2}\left[F O O D_{t k}, \quad N U R S_{t k}, W E A N L_{t}, S E V E R E . D I A R_{t-1}\right. \text {, } \\
& \text { MILD.DIAR }{ }_{t-1}, \text { PR.SICKNESS, } \\
& {\left[F O O D^{*} P R . D I A R\right]_{t k}, S E X_{k}, B R T H O R D,(\# C H<6),} \\
& \text { INT'VL, EDMO, EDFA, AGEFA, AGEMO, } \\
& A G E D U M_{t k}, \quad P R O M O_{t k}, \text { BRTHCON, WTHT } T_{t-1} \text {, } \\
& \left.H T A G E_{t-1}, \varepsilon_{2}\right] \text {, }
\end{aligned}
$$

\footnotetext{
${ }^{12}$ These measures are preferred to simply using a child's weight-for-age (WTAGE) (i.e., its weight compared to the med"an weight of a large sample of children of the same age). The $W T A C E$ measure is highly sensitive to family uncertainty as to a child's precise age in months and may overestimate the extent of the malnutrition problem [see Heller and Drake (1976), Waterlow (1973, 1974), and Habicht (1974)]. Other standards, for measuring nutritional status are available, including an arm circumference measure, clinical tests for the oedema and marasmus rates, and laboratory tests for hemoglobin and serum albumin levels. See Zerfas et al. (1975) for a survey of such standarts.

${ }^{13}$ In both cases, the median score is 100 . For the source of these standards and for a summary of the teckniques used to develop them, see National Center for Health Statistics (1976).

${ }^{14}$ NAS 11973), Cravioto (1973), Cravioto in Scrimshaw and Behar (1976), and Garn (1975).
} 


$$
\begin{aligned}
& W T A G E_{t k}=N_{3}\left[F O O D_{t k}, N U R S_{t k}, W E A N L_{t}, \text { PR.SEVERE.DIAR }{ }_{t k},\right. \\
& \text { PR.MILD }{ }_{t k}, \text { PR.SICKNESS, } \\
& {\left[F O O D^{*} P R . D I A R\right]_{t k}, S E X_{k}, B R T H O R D,(\# C H<6) \text {, }} \\
& \text { INTVL, EDMO, EDFA, AGEFA, AGEMO, } \\
& \left.A G E D U M_{t k}, \text { PROMO }_{t k}, B R T H C O N, W T A G E_{t-1}, \varepsilon_{3}\right] \text {, }
\end{aligned}
$$

where $k$ refers to an observation on a child when it is in the $k$ th age group. Table 1 displays the definitions of the variables used in the empirical analysis as well as thir mean and standard deviation (where applicable). The variables relate specific policy isstes and hypotheses about the process of nutritional change:

(1) What is the impact of varying the level and composition of utrient intake on nutritional status at different ages? Lacking measures of the actual nutrient input to a child at a particular point in time, we must rely on the level of real femily food expenditure per capita $(F O O D)^{15}$ and on whether the child was aursing at the time of the observation. Multiplicative dummy terms are used to differentiate the impact of food expenditure by age group $\left(2-11,12-23,24-47\right.$, and over 47 months). ${ }^{16}$ Aithough this is a reasonable proxy for food intake for a weaned child, it is not as accurate as would be desired for pol icy analysis for the entire sample. ${ }^{17}$

Similarly, four variables have been developed to capture the effects of nursing and veaning; the percentage of a child's life nursed, for children in the first and second years of life (PCT. of 1st yr. NURSED, PCT. of 2nd yr. NURSED), respectively; the absolute number of months nursed for children over 24 months of age, a ad an additive dummy term for observations occuring durirg the weaning period. ${ }^{18}$ The Iirst two atternpt to capture any

\footnotetext{
"1 $t$ would have been preferable to adjust the cize of household by the norm nutritional demands of its inembers.

${ }^{16}$ In section 4 , we have described the method used in specifying the multiplicative dummy tera:

${ }^{17}$ There is a legitimate problem of interpretation of the food expendiiture variable. The variable measures real food expenditure in the household, where the divisor is simply the number of persons in the household. If a child were only breast fed at time $t$, food would only be a factor influencing its nutriticnal status to the extent that the qualizy and quantity of milk is contingent on the level of maternal nutrient intake. The divisor wou'd, therefore, only be accurate if the mothe 's corisumption were twice as large as other household members. After we-ning, our measure is accurate if one assumes equal sharing of food within the household. 17. problein is rendered more complex where children are only partially weaned.

1 The data in our sample included information on whether a child was nursing at the time of the visit. Given multiple observations on each child, there are three classes of children -- those who are still nursing, those who have not been nursed during their participation in the program, and those for whorn the timing of the termination of breastfeeding cannot be established. For the last group, the midpoint age between the nursing and off-nursing observations is taken as the age weaned; for the middle group, the midpoint age between our earliesi observation on the child and birth is assumed as the age weaned; for the former, group, cornplete weaning has not yet occurred.
} 
Table 1

List of variables with means and standard deviation in parentheses. ${ }^{a}$

\begin{tabular}{|c|c|}
\hline$W T H T_{t}$ & $\begin{aligned}= & (100) \times \text { (ratio of a child's weight to median weight of children of } \\
& \text { same height and sex, using NAS standard })(100.27,10.59) .\end{aligned}$ \\
\hline$W T A G E_{\imath}$ & $\begin{aligned}= & (100) \times(\text { rat } i s \text { of a child's weight to median weight of children of } \\
& \text { same age and sex, using NAS standard })(91.49,11.04) .\end{aligned}$ \\
\hline$H T A G E_{t}$ & $\begin{array}{l}=(100) \times(\text { ratio of a child's height to median height of children of } \\
\text { same age and sex, using NAS standard })(95.09,4.93) .\end{array}$ \\
\hline$\triangle W T H T_{t}$ & $=W T H T_{t}-W T H T_{t-1}$ \\
\hline BTHWGHT & $\begin{array}{l}=\text { Weight of child for earliest observation before age } 2 \text { months, if } \\
\text { child is } 0-11 \text { months; necessary to ornit observation if child is } 0- \\
11 \text { months with no birthweight data; } 0 \text { otherwise (in } 100 C \text { grams). }\end{array}$ \\
\hline STUNTED $D_{t-1}$ & $=1$ if child's $H T A G E$ score is less than 90 in period $t-1,0$ otherwise. \\
\hline$M A L N O U R_{1-1, k}$ & $\begin{array}{l}=1 \text { if a child in the } k \text { th age group has a } W T H T \text { score less than } 90 \\
\text { in period } t-1,0 \text { otherwise. }\end{array}$ \\
\hline$F_{0 O D}$ & $\begin{array}{l}=\text { Weekly real food expenditure per capita within th } 2 \text { household in } \\
\text { period } t \text { in } 1968 \text { pesos }(253.5,156.3) \text {. }\end{array}$ \\
\hline WEANL & $\begin{array}{l}=1 \text { if observation is during or directly afte: weaning (the latter, } \\
\text { within } 3 \text { months) }(0.23,0.42) \text {. }\end{array}$ \\
\hline$N U R S_{t k}$ & $\begin{array}{l}=\text { Includes the variables: (i) Months Nursed, (ii) Pct. of } 1 \text { st yeär } \\
\text { nursed, (iii) Pct. of } 2 \text { nd year nursed, and (iv) WEANL, as defined } \\
\text { above. }\end{array}$ \\
\hline MONTHS NURSED & $\begin{array}{l}=\text { For children over } 23 \text { months, age of child at which it terminated } \\
\text { nursing; } 0 \text { otherwise }(9.05,6.53)(11.69,7.85 \text { on sample of children, } \\
\text { aged } \geqq 24 \text { months). }\end{array}$ \\
\hline $\begin{array}{l}\text { PCT. OF ISTYR. } \\
\text { NURSED }\end{array}$ & $\begin{array}{l}=\text { For children }<12 \text { months, fraction of its age it has been nursed; } \\
\text { for all others, } 0(0.80,0.29 \text { on sample of chiclren aged } 0-11 \\
\text { months). }\end{array}$ \\
\hline $\begin{array}{l}\text { PCT. OF } 2 N D Y R . \\
\text { NUURSED }\end{array}$ & $\begin{array}{l}=\text { For children with } 12 \text { months } \leqq \text { age }<24 \text { months, fi action of its age } \\
\text { it has been nursed; for all others, } 0(0.49,0.30 \mathrm{cn} \text { children aged } \\
12-23 \text { months). }\end{array}$ \\
\hline AGE WEANED & $=$ Number of months before hild was weaned $(10.7:, 7.15)$ \\
\hline$S E X$ & $==$ Sex of child $($ boys $=0$, girls $=1$ ) \\
\hline BRTHORD & $=$ Birth order of the child within the household $(4.11,2.54)$ \\
\hline INTVL & $\begin{aligned}= & \text { Number of months between age of child and its predecessor; if no } \\
& \text { previous child, } I N T V L=72(46.4,22.31) .\end{aligned}$ \\
\hline$\# \mathrm{CH}<6$ & $\begin{aligned}= & \text { Total number of children in the household of age less than } 72 \\
& \text { months }(2.3 .1,0.96) .\end{aligned}$ \\
\hline$E D F A$ & $\begin{array}{l}=\text { Educational level of the father }(1=\text { illiterate, } 2=\text { read \& write only, } \\
3=\text { primary school (grades } 1-5), 4=\text { secoridary school (grades } \\
\text { 6-11), } 5=\text { technical }(2.78,0.76)\end{array}$ \\
\hline EDMO & $=$ Educational level of the mother (as abovi) $(2.79,(0.73)$ \\
\hline$A G F A$ & $=$ Age of father in years $(35.52,8.47)$ \\
\hline AGMO & $=$ Age of mother in years $(29.06,6.50)$ \\
\hline BRTHCON & $\begin{aligned}= & 1 \text { if mother used the pill "I IUD for birth control; } 0 \text { otherwise } \\
& (0.38,0.48) .\end{aligned}$ \\
\hline
\end{tabular}


Table 1 (continued)

List of variables with means and standard deviation in parentheses.a

\begin{tabular}{|c|c|}
\hline$P R O M O_{t k}$ & $\begin{array}{l}=\text { Percentage of child's life it was in the Promotora program, at time } \\
t \text { for child of age } k(0.84,0.24) \text {. }\end{array}$ \\
\hline$D P T$ & $\begin{array}{l}=1 \text { if child ever received a DPT immunization; } 0 \text { otherwise }(0.14 \text {, } \\
0.19 \text {. }\end{array}$ \\
\hline OLIO & $\begin{array}{l}=1 \text { if child ever received a polio immunization; } 0 \text { otherwise }(0.10 \text {, } \\
0.17) \text {. }\end{array}$ \\
\hline$I N C O M E_{t}$ & $=$ Monthly family income in 1000 real 1968 pesos $(1253.1,950.7)$. \\
\hline$Y E A R_{\imath}$ & $=$ Calendar year associated with observation in period $t$ \\
\hline PRENAT & $=1$ if mother ever received prenatal care; 0 otherwise $(0.31,0.46)$ \\
\hline SICKNESS & $\begin{array}{l}=1 \text { if child was ill since previous visit by promotora: } 0 \text { otherwise } \\
(0.24,0.43) \text {. }\end{array}$ \\
\hline PR. SICKNESS & $\begin{aligned}=\text { Estimated probability that child was ill since previous visit by } \\
\text { promotora }(0.25,0.08) \text {. }\end{aligned}$ \\
\hline DAYS SICK, & $=$ Number of days sick since previous visit by promotora. \\
\hline$M I L D I I A R_{t k}$ & $\begin{array}{l}=1 \text { if child had } 1-4 \text { days of diarrhea during the month preceding } \\
\text { visit in time } t, 0 \text { otherwise, where diarrhea is defined as more than } \\
3 \text { loose stools per day; for a child in } k \text { th age group }(0.08,0.27) \text {. }\end{array}$ \\
\hline PR. MILD DIAR & $\begin{array}{l}=\text { Estimated probability that child had a mild diarrhea episode } \\
\text { during month preceding visit in time } t(0.07,0.04) \text { for a child in } k \text { th } \\
\text { age group. }\end{array}$ \\
\hline$S E V E R E D I A R_{t k}$ & $\begin{array}{l}=1 \text { if child has had more than } 4 \text { days of diarrhea during the month } \\
\text { preceding visit in time } t ; 0 \text { otherwise, for a child in } k \text { th age group } \\
(0.08,0.27) \text {. }\end{array}$ \\
\hline PR. SEVERE DIAR & $\begin{array}{l}=\text { Estimated probability that child had a severe diarrhea episode } \\
\text { during month preseding visit in time } t \text {, for a child in } k \text { th age } \\
\text { group }(0.07,0.03) \text {. }\end{array}$ \\
\hline$[(F O O D)(P R . D I A R)]_{\imath k}$ & $\begin{array}{l}=\text { Product of weekly food expenditure per capita in the household } \\
\text { and the probability of a diarrhea episode in time } t \text { for a child in } \\
\text { the } k \text { th age bracket. }\end{array}$ \\
\hline$A G E D U M_{t k}$ & $\begin{array}{l}=\text { This includes dummy variables for (i) age, } 0-11 \text { months, (ii) age, } \\
12-23 \text { months, (iii) age, } 24-35 \text { months, (iv) age, } 36-48 \text { months, (v) } \\
\text { age, } 49-72 \text { months, as described below. }\end{array}$ \\
\hline$A G E, 12-23$ months & $=1$ if child is aged $12-23$ months; 0 otherwise. \\
\hline$A G E, 24-35$ months & $=1$ if child is aged $24-35$ months; 0 otherwise. \\
\hline$A G E, 36-48$ months & $=1$ if child is aged $36-48$ months; 0 otherwise. \\
\hline$A G E, 49-72$ months & $=1$ if child is aged $49-72$ months; 0 atherwise. \\
\hline$A G E, 0-1 i$ months & $=1$ if child is aged $0-11$ months; 0 otherwise. \\
\hline$\triangle A G E_{i, t-1}$ & $\begin{array}{l}=\text { Change in age in months between period } t \text { and } t-1 \text { for given } \\
\text { child. }\end{array}$ \\
\hline
\end{tabular}

${ }^{a}$ We have cmitted the $i$ th term for child and $j$ th term for family where it is clear. The $t$ subscript refers to the current observation on any child. The spacing between $t$ and preceding anc subsequent observations is child-specific. 
non-linearity over time in the impact of nursing. ${ }^{19}$ The third evaluates whether the length of time a child is nursed has any residual impact on the child's nutritional status after it has been weaned. The !ourth attempts to isolate any heightened risk to nutritional status during the weaning period.

(2) If a model of nutritional status did not take account of a child's health status, the coefficients of nutrient variables would be seriously biased. The impact of nutrients is contingent on the efficiency of nutrient utilization, and this will be affected by a child's health. Since the number and timing of our observations on any particular child varies considerably, it is impossible to reconstruct a child's medical history. This is exacerbated by the fact that our survey indicates only the duration of a diarrheal episode in the month preceding the promotora visit. The lack ol refinement in these morbidity measures obviously weakens the explanatory power of the model. Even these variables are themselves subject to significant recall inaccuracy. Recent studies suggest that parental recall of diarrheal episodes more than 15 days past is subject to considerable error ${ }^{20}$

For our model, we have identified three illness variables: whether or not the child had (i) a mild diarrheal episode, lasting one to four days during the previous month (MILD.DIAR $R_{t k}$ ), (ii) a severe diarrheal episode lasting more than 4 days (SEVERE.DIAR rtk ), and (iii) any other illness since the previous visit of the promotora $\left(\text { SICKNESS }_{t}\right)^{21,22}$ As a consequence of the econ. omeiric estimation procedure used, instruments for these ihree variables are created that indicate the prubability of a mild liarrhea episode (PR.MILD.DIAR.), the probability of a severe darrhea episode (PR.SEVERE.DIAR.), and the probability of another illness episode (PR.SICKNESS) during the aforementioned time periods. The distinction between a mild and severe diarrheal episode reflects the bimodal distribution of the data, our own doubts that a finer distinction can be reliabiy drawn from the data, and the likely correspondence between these measures and toxic and infectious diarrhea, respectively. ${ }^{23}-$ ere episodes should have a

\footnotetext{
${ }^{19} \mathrm{We}$ did not simply use the 'number of months nursed since it is likely to be highly colinear with inge.

${ }^{20}$ In fact, studies have shown that recall accuracy declines significantly after one week [Wocdward (1973)].

${ }^{21}$ Each observation on a child was taken at the time of a visit by the promotora to a child's family (as discussed in section 3). Although visits were made every two mor ths, our data include a sample of observations chosen to be approximately 6 months apart.

${ }^{22}$ The probability of sickness for a child in Candelaria is high. The protability of a mild and severe diarrhea erisode is approximately 0.075 and 0.08 respect vely, during any month in the first year of a child's life and 0.095 and 0.097 , respectively, during, any month in the second year. The probability of other kinds of illness (principally respiratory) i: 0.24 .

${ }^{23}$ The distribution of diarrhea in the previous month, by days of duration, is as foilows: 0 days $-8.1 \%, 1$ day $-0.7 \%, 2$ days $-2.1 \%, 3$ days $-2.4 \%$, days $-1.4 \%, 5-10$ days $-5.0 \%$, $11-20$ days $-1.6 \%$, $21-90$ days $-1.4 \%$.
} 
more deleterious effect on nutritional status, particularly $W T H T$. However, it should be noted that even if a child registers one of these disease episodes, it may be consistent with alternative medical problems of varying degrees of severity, each with a different impact on nutritional status. Thus, the statistical impact of any illness variable is likely to reflect the composite effect of the underlying disease problems.

It is important to specify accurately the dynamics of the impact of any illness episode. Whereas diarrhea or illness may have an immediate effect on a child's weight, and thus its WTHT or WTAGE score, it is likely to influence a child's height only over the medium term. In our HTAGE model, we test for the impact of a severe or mild level of diarrhea in the month preceding the $t--1$ st observation. As above, multiplicative dummy variables arc used to measure the differential impact of diarrhea across age groups.

To measure the impact of diarrhea on the body's food utilization efficiency, we introduce a nonlinear variable, $[(F O O D)(P R . D I A R .)]_{t k}$ where $\left[P R . D I . A R_{\imath t}\right]$ is the estimated probability that a child will have a diarrhea episode in time $t$ for $a$ child of age $k$. There are two opposing processes implicit in the product of these two variables. The higher the likelihood of diarrhea, the weaker will be the impact of any dollar of food expenditure, thus yielding a negative coefficient for this variable. Yet in the context of a given probability of diarrhea, the greater the food expenditure, the smaller the negative nutritional impact of the diarrhea. The sign and significance of the coefiicient suggests which of these two relationships is the dominant one, though both may be present and significant.

(3) It is possble that parents 'discriminate' between children in their allocation of pesources and time (e.g., against girls or higher birth order children). The model tests the hypothesis that the sex (SEX) or birth order (BRTHORD) of a child has an influence on its nutritional status. ${ }^{24}$

(4) Pareftal ability to provide adequate resources and attention for any child is weakened by the extent of implicit competition with other siblings. Children for whom the birth interval with a preceding child is particularly short (INTVL) maly be deprived of their proportionate share of family resources. A child in a family with a large number of young siblings under 6 ( \# $\mathrm{CH}<6$ ) may also obtain fewer resources. Both factors should be reflected in a lowered nutritional status.

(5) The nutritional impact of a given level of food expenditure is not independent of a parent's knowledge of personal and food hygiene. Since parental human capital accumulates either through experience or through

\footnotetext{
${ }^{24}$ The NAS standards are ostensibly sex-specific. Although there may be some tendency for birth order to influence a child's neonatal nutitional status, one would not expect such differences to be compelling beyond the first year $o$ : life.
} 
education, we include measures of the formal educational level of mothers and fathers (EDMO,EDFA) and of the age of the mcther and father $(A G E F A, A G E M O)$ ). One might hypothesize some ambiguity in the impact of these variables. Age is not only correlated with experience but with diminished physical energy, possible fatalism and a lower potential rate of return on investments in child quality. Children of older mothers a.re likely to be of lower birthwight. Higher education may promote values detrimental to child health (e.g., early weaning and improper use of bottled milk). ${ }^{25}$

(6) Though our nutritional measures either correct for age or are age independent, additive age dummies $\left(A G E D C^{\prime} M_{t k}\right)$ for each of the first four years of life were included to measure any trends in nutritic nal scores over a child's early years. ${ }^{26}$ This provides a more accurate test of the hypothesis of an earlier study that there is a 'natural history' of nutritional development reflected by a fall in nutritional status after the first 12 months with a rise after 48 months. $^{27}$

(7) To assess the Promotora program's impact, we have developed a measure of the degree of program participation. Since a child could have entered the program at any point in its life, ${ }^{28}$ the fractiol: of its life in the prcgram, for children of the same age, is one possible measure of the degree of participation. Yet across children of different ages, one might expect that the longer a child has been in the progran, the more beneficial the impact. ${ }^{29}$ To capture both effects, we create multiplicative dummy terms measuring the fraction of the child's life in the program, according to whether the child is aged one, two, three or four or more years $\left(P R O M O_{t k}\right)$. Since the Promotora pr Jgram also disseminated family planning information, 've hypothesize that parental use of modern birth control methods (BRTHCON) proxies the degree and enthusiasm of their participation in the program.

(8) The process of nutritional change is a dynamic process. At any point in tine, a child's nutritional status is not likely to change dramatically from the previous period. Similarly, genetic factors, as proxied by parental height or maternal stature, are likely to have significant explanatory power, particularly in the $1 T$ T AGE equation. ${ }^{30}$ Unfortunately, our study lacked parental physical attribute measures. Lacking these, the lagged dependent variable

\footnotetext{
${ }^{25}$ See Wray and Aguirre (1969).

${ }^{26}$ Such dumrnies take on the value 1 if a child is within a given age bracket, zero othervise.

${ }^{27}$ Drake and Fujardo (1976).

${ }^{28}$ Altiough in principle children enter the prograin at birth, children of new migrant families and others not previously reached by the program entered later.

${ }^{29}$ The 'number of months' in the program is collinear with age.

${ }^{30}$ Tanner has documented that the significance attributed to anthropometric measures may be modified if apjropriate corrections for parental height are introduced. Tanner (1966).
} 
had to serve as a correlated measure of genetic background. Since the timin 5 of an observation was determined by when the promotora visited the child's family, it is necessary to ensure some comparability in the time frame between visits. It would be misleading if the gap between the $t$ and $(t-i) s t$ observation of two children differed widely (e.g., 2 vs. 24 months). Thus, one period lags are taken only when the time difference between observations is 3 to 9 months. ${ }^{31}$

\subsection{Health status model}

Although it would be useful to specify (2) by examining the risks of illness from the separate disease agents to which a child is commonly ex posed, we have noted that our data is limited to information on the duration of diarrhea episodes and of the occurrence of other kinds of illness since the previous visit by the promotora. Both measures of illness carry a heavy subjective element, depending upon the accuracy of parental recall and differing perceptions of 'abnormality' in healthy status. Medicsl problems without obvious or unusual symptoms may pass unnoticed by the parent. Given the questionabie accuracy of the data, we limited ourselves to three dichotomous dependent variables: MILD.DIAR ${ }_{r k}, S E V E R E . D I A R_{r k}$, and SICKNESS $S_{t}$ as described above and in table 1.

Despite its frequency, the etiology of diarrhea disease remains unclear. Morley comments that 'the diarrheal stool has been a happy but rather barren hunting ground for microbiologists for many years. ${ }^{32}$ No single pathogenir agent is prinarily responsible, and only in a quarter of cases can any specific pathogen be isolated at all. Discussions of the disease inevitably focus on circumstances in which the risk is greatest.

Children are presumed to be most susceptible during weaning. Their exposure is greatest (as they use their mouth to identify objects and kecause of their newly found mobility). At that time, their level of immunity to new patl ogenic agents is lowest and their vulnerability to substitution of an inadequate and imbalanced diet greatest. Potential exposure to feces-borne disease agents is most serious in environments with inadequate waste disposal methods and/or low volumes of water usage, since this influences both the presence and density of disease agents. Malnourished children are most at risk since there is evidence that their cellular immunity is lower because of the impact of malnourishment on the thymus gland. ${ }^{33}$

The specification of the structural equations to explain the occurrence of a mild or severe diarrhea episode in (6) below reflects both these con-

\footnotetext{
${ }^{31}$ The average interval between obser yations is 5.4 months, with a standard deviation of 1.96 months.

${ }^{32}$ Morley (1973).

${ }^{33}$ Ibid.
} 
siderations and some of our sarlici hypet1. us cuncerning the impact of ivisuinic and aemographic factors on bealth status. Our specification for the occurrence of othes illnesses iri (7) is assumed identical to (6), ${ }^{34}$

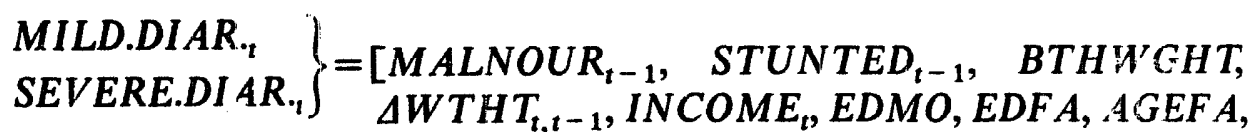

$$
\begin{aligned}
& \text { AGEMO, SEX, BRTHORD, (\#CH<6), INTVL, } \\
& \text { NURS }{ }_{t k}, W E A N L_{l}, \text { DPT, POLIO, PRENAT, } \\
& \text { BRTHCON, PR.SICKNESS, AGEDUM }{ }_{t k} \text {, } \\
& \left.P_{R O M O}{ }_{t k}, Y E A R, \varepsilon_{4}\right] \text {, }
\end{aligned}
$$

(1) Poor nutritional status may heighten the risk of illness. Two dummy variables are included to distinguish children with WTHT or HTAGE scores lower than 90 in the previous period $\left(M_{\text {ALNOUR }}\right.$ I $\left._{t-1, k}, S T U N T E D_{:-1}\right)$. For infants, birthweight $(B T H W G H T)$ is probably the best indicator of initial nutritional status. After the first year, the effect of birthweight declines relative to current nutritional status.

(2) Changes in weight or height are often argued to be useful clinical indicators of a child's risk of morbidity. A child with a high WTHT or HT AGE score but experiencing a significant slowing in the rate of growth in weight or height may be clinically more at risk to illness than a child with a low percentile position that is stable or exhibiting improvement. ${ }^{35}$ Since it is a sudden weight change that is the primary source of concern, only a change in $W T H T$ percentile position has been isucied. In the structural equation system, $A W T H T_{t, t-1}$ is endogenous.

(3) The ability of parents to provide inputs $M_{i j t}$ to insulate a child from the risks of morbidity is measured by real family income per capita $\left(I N C O M E_{t}\right)$. Differences in parental child-rearing efficiency are proxied by the educational level and age of the parents.

(4) Parental priorities in allocating family resources are tested by the sex and birth order variables; the effect of family competicion by variables measuring the birth interval and the numbe: of siblings under age 6.

\footnotetext{
${ }^{34}$ The specifications for the mild and severe diarrhea equations are icientical.

${ }^{3}$ Morley (1973).
} 
(5) A child is often exposed to illness through the poor quality of food and its unhygienic preparation. We hypothesize this exposure to be lowest during the period the child is breastfed. A dummy variable tests any increased sensitivity of a child to diarrhea and other diseases during the weaning period (WEANL).

(6) The receptivity of parents to preventive medical services may be indicative of their attitude toward hygiene and health care. Several proxy indicators are available: (i) whether a child received a D.P.T. or polio immunization (DPT, POLIO); (ii) whether a mother received any prenatal care (PRENAT); and (iii) whether she uses a modern method of birth control (BRTHCON).

(7) Since the onset of diarrhea may be induced by other illuesses, the specifications of the diarrheal equations include an estimate of the probability of sickness for the child.

(8) Dummy variables for a child: age test for any non-linear reduction in the risk of morbidity obtained thiough exposure to pathogenic agents over its early years.

(9) The impact of the Promotor , program on child health is tested using the indicators of program participe ion discussed above.

(10) Finally, the occurrence of diarthea or illness is likely to be seasonally correlated. Since we cannot date each observation, this cannot be tested in the model. A calendar year variable is introduced to capture any change over time in the quality of the environment arising from program activities or other factors.

\subsection{Parental decisions on nutrient intake}

We also use the framework of parental choice to explain: (i) the age at which the child is weaned from breast feeding, and (ii) the level of food expenditure per cal ita in the household. The length of time a child is breast fed reflects both cultural and economic considerations. In many ceveloping countries, modernization is accompanied by reduced reliance on breast feeding. The higher the opportunity cost of the mother's time, the greater the effect since it raises the price of breast feeding relative to bottle-feeding. The higher the income and education levels of a family, ceteris paribus, the earlier the age of weaning. Since the Promotora programs stressed breast feeding, one would expect a positive correlation between progran participation and age at weaning. The mother's physiological capacity to breast feed wotld influence the age of weaning, and this might be negatively related to a child's birth order or maternal age. This model is estimated on the set of 
observations taken at the time of weaning for all children for whom precise weaning data could be derived. The model specification is

$$
\begin{aligned}
\text { AGE WEANED }= & {\left[I_{N C O M E_{t}, \text { PROMO }},\right. \text { PRENATAL, }} \\
& \text { BRTHORD, SEX, AGEMO, INTVL, } \\
& \text { EDMO, EDFA, (\#CH<6), } \left.\varepsilon_{6}\right] .
\end{aligned}
$$

A model that explains the level of real food expenditure per capita in the household is important for policy analysis of some nutritional program alternatives. Evaluation of any program that focuses on income transfers (and possibly even nutritional supplementation) must measure the potential leakage that will emerge between the growth in income and ultimate changes in nutritional status. This requires an estimate of the initial leakage of income to non-food expenditure. A conventional demand equation of the following form is used:

$$
F O O D=\beta_{0} I N C O M E^{\beta 1}(\# C H<6)^{\beta 2}(E D M O)^{\beta 3}(E D F A)^{\beta 4} \varepsilon_{7} .
$$

Dividing by INCOME and taking logarithms, this was estimated as

$$
\begin{aligned}
\ln \frac{F O O D}{I N C O M E}= & \ln \left(\beta_{0}\right)+\left(\beta_{1}-1\right) \ln I N C O M E+\beta_{2} \ln (\# C H<6) \\
& +\beta_{3} \ln (E D M O)+\beta_{4} \ln (E D F A)+\ln \varepsilon_{7},
\end{aligned}
$$

where $\beta_{1}$ is the income elasticity for food expenditure in the household.

\section{The data}

Even though this is a highly simplified model of health and nutritional status, the data requirements for its estimation are substantial, particularly in the context of a developing country. It requires longitudinal data on the physical development and health status of the child, data on nitritional inputs as well as detailed longitudinal socioeconomic and demographic data on the characteristics of the family in which the child is a member. The Candelaria dara base is unusual in that it satifies these requirements.

The Promotora program was established in 1968 to provide home-based preventive and maternal child health services. Its major objective was to prevent childhood diseases as well as to reach children before illness had progressed to a point requiring, extensive and costly medical treatment. Ten volunteer health workers, promotoras, aged 16 to 21 and with at least five years of primary school education, were given six months of triining. All families with children less than six years of age were visited every two 
months. The promotoras provided information on autrition, hygiene and the role of modern medical services, gathered data on each child's height and weight, and referred sick children to a health center staffed by paramedical workers. Pregnant and lactating mothers were also instructed in pre-natal and post-natal care. The promotcras regularly collected demographic, medical and socioeconomic data on both the family and the individual child.

At the time the family entered the Promotora program, socioeconomic data were obtained on each family, along with data on the health status of each child. Thereafter, health and nutritional status data on the children were obtained during each visit of the promotora to the family. In addition, there was an annual update on the family's composition, monthly income, weekly food expenditure and method of birth control. Our sample consists of multiple observations on 1,270 children $^{36}$ made between 1970 and 1974. There are one to five observations per child, with an average of three (taking account of a one period lag). A considerable amount of effort was iivested in 'cleaning' this survey data, either by eliminating clearly spurious or logically inconsistent data $\mathrm{c}^{*}$ by referring to source documents to correct questionable answers. ${ }^{37}$

Candelaria is a small town $30 \mathrm{k}$ ometers from Cali. It is a transient community, principally composed of migrants from the outlying rural areas who ultimately emigrate to Cali or other larger urban areas. This is reflected by an annual population growth rate of $10 \%$, despite an estimated outmigration rate of $17 \%$. The principal sources of employment are the sugar cane plantations and sugar processing factories. Although there is some home producion of vegetailes and other foodstuffs, most of the population appears to depend on cash income for survival. The average monthly income level in the community is less than U.S. \$31).00.

Candelaria is unusuct for its proximity to an active and innovative medical research and educational center, one which had an operational rural health program for 6 to 10 years prior to the inception of the Promotora program. ${ }^{38}$ In the Candelaria municipality proper, $67.7 \%$ of the homes inside the city had sanitary waste facilities and $90.9 \%$ had piped water inside thei homes by $1964 .{ }^{39}$ Consequently, the rate of malnourishment in Candelaria is

\footnotetext{
${ }^{36}$ Our sanple was chosen from a larger clata set containing observations on over $80 \%$ of all children under six years of age in the town. Observations of children during 1968 and 1969 were excluded since th. yy lacked information on a child's height. For a more detailed description of Candelaria and of the Promotora program, see Drake and Fajardo (1976).

${ }^{37}$ Several computer programs were written which performed range comparisons and logical consistency cilecks among different variables. A full description of this methodology is cr.tai ed in the report on Community Level Nutrition Interventions, available through Comr urity Systems Foundation, Arin Arbor, MI.

${ }^{38}$ For example, for a 14 month period beginning in 1964, weekly food supplements ware distributed to each person of nutritionally vulnerable age (pre-school children, pregnant and nursing mothers). Mothers in groups of 25 to 30 took part in seven educational presentations

${ }^{39}$ These numbers are likely to be overestimates for the Promotora client population, since ine latter are drawn from a wider arza.
} 
lower than the nationa! average for Colombia; only $30 \%$ of its children were malnourished in 1963 on a WTAGE standard compared to $55.6 \%$ nationally in 1965.

The absence of severe, widespread malnutrition in the Candelaria area is also clear fron our sample. Although $32 \%$ of the children in the sainple had WTAGE sccres below 85 , more than $80 \%$ of the children had a WTHT score above 85 . In fact, despite a mean WTAGE score of 92.0 for the sample, the mean WTHT score was 100.3. Although the Cancelaria population is short relative to the N.A.S. standard, with a mean $H T A G E$ score of $95.5,{ }^{40}$ significant stunting is even more limited than acute malnourishment. Only $3 \%$ of observations are on children scoring below 85 in erms of $H T A G E$. The implications of using such a sample musi be noted. The fact that the sample is not heavily weighted with extreme cases of malnutrition implies that our model is likely to be inefficient in estimating the detailed relationships between malnutrition and morbidity among the severely malnourished. Conversely, because there are many children in the sample with normal as well as abnormal development patterns, our data are more likely to capture the variabies that do clifferentiate those children that are ill or malnourished. Nevertheless, it is clear that the results should be interpreted and applied with caution.

\section{Econometric issues}

The estimation of the model requires three principal adjustments for deviations from the assumptions of the classical regresion model (OLS). First, OLS estimation would be int:ficient for the three dependent variables which are dichotomous, dur to heteroscedasticity, aud misleadir y fur predictive purposes, since there is no guarantee that the predicted $Y$ would be in the interval $(0,1)$. A maximum likelihood estimation procedure - logit - of the form

$$
\log \left[\frac{P\left(Y_{i n}=1\right)}{\left(1-P_{i t}\left(Y_{i t}=1\right)\right)}\right]=\alpha_{0}+\alpha_{1} X_{1 i t}+\alpha_{2} X_{2 i t}+\ldots+\alpha_{n} X_{i i}+\varepsilon_{i t},
$$

is used where, for example, $P\left(Y_{t}=1\right)$ is the probability that the ith child had a sever: diarrhea episode in period $t .^{41}$

Second, the model suggests the possibility of simultaneous equations bias, and thus the structural equations are estimated using two stage leiast squares (TSLS). Instruments for the included endogenous variables - SEVERE

\footnotetext{
${ }^{40}$ It is quite possible that if parental heigh: were taken into account, the in:tgnitude of the alleged deficiency would decrease and possibly disappert.

${ }^{41}$ For a fuller discussion of the problems of estiviatirg equations with dichotımous dependent variables, set Kmenta (1971) and DuMouschel (n d.).
} 
DIAR, MILD DIAR., and SICKNESS - in (3), (4), and (5) are estimated from a first stage logit estimation on the entire set of exogenous variables. These instruments measure the predicted probability of particular disease episodes. ${ }^{42}$

Finally, one might expect corsiderable non-linearity in many of the relationships of the model. An important motivation for the use of an anthropometric standard rather than the absolute level of weight and height is to adjust for non-linearity with age. Much of the remaining non-linearity relates to changes in potential structural coefficients as a child progreses in age; this is dealt with through multiplicative dummy terms (see footnote i vi table 2). Since it is the first three years that are the most critical for a child's nutritional development and its risk of illness, the non-linearities durirg this period are particularly important. The cut-off ages are 12, 24, 36 and ccasionally 48 months. This suggests the possibility of some bias in our sefficients if the cut-off ages are incorrect.

\section{Estimation results}

Table 2 displays the econometric estimates of the structural model of nutritional status of (3), (4) and (5); and table 3 presents estimates of the model of health status, of the determinants of the age of weaning and of the level of food expenditure. To assess the impact of policies on nutritionally vulnerable childiren, the model is also estimated on the restricted sample of children that have ever suffered any degree of malnourishment. ${ }^{43}$

Interactions of health and nutritional status. Our results confirm that the timing and severity of a diarrheal episode determine its nutritional impact. From table 2, eq. (2) severe diarrhea in the e rly part of the first year of life has a highly significant, negative effect on a child's structural development in the course of that year, with a loss of almost five points in HTAGE. ${ }^{44}$ This might explain the unusual positi"e coefficient for severe diarrhea in term; of WTHT score in the first year, since the child's weight may be less adversely

\footnotetext{
${ }^{42}$ Since the data set represents a pooling of cross section and time series observations, tests for autocorrelation were mad: by estimating a first order antocorrelation coeflicient. In the equations for diarzicica auc sicikness, $\rho$ is low, ranging from -0.01 to +0.03 . Using the test suggested by Durbin (1970) for autocorrelation when some regressors are lagged dependent variables, one may reject the possibility of autocorrtiation at a $90 \%$ confidence level in the nutritional status equations.

${ }^{43}$ For the $W T H T, W T A G E$ and $H T A G E$ equations, the samples include all observations on any child that has ever had (i) a WTHT score less than 85, (ii) a WTAGE score less than 85 , and (iii) a HTAGE score less than 87, respectively. The results are reported in tables 2 and 3.

${ }^{44} \mathrm{Frcm}$ Heller (i976) the contemporaneous effect of a severe diarrhea episode in the first six months of life on HTAGE is not significant. In the HTAGE equation [table 2, eq. (2)], we capture the effect on cliarrhea in the previous poriod. Thus, for infants, we are observing the effect on $H T A G E$ in the !atter half of a child's first year.
} 


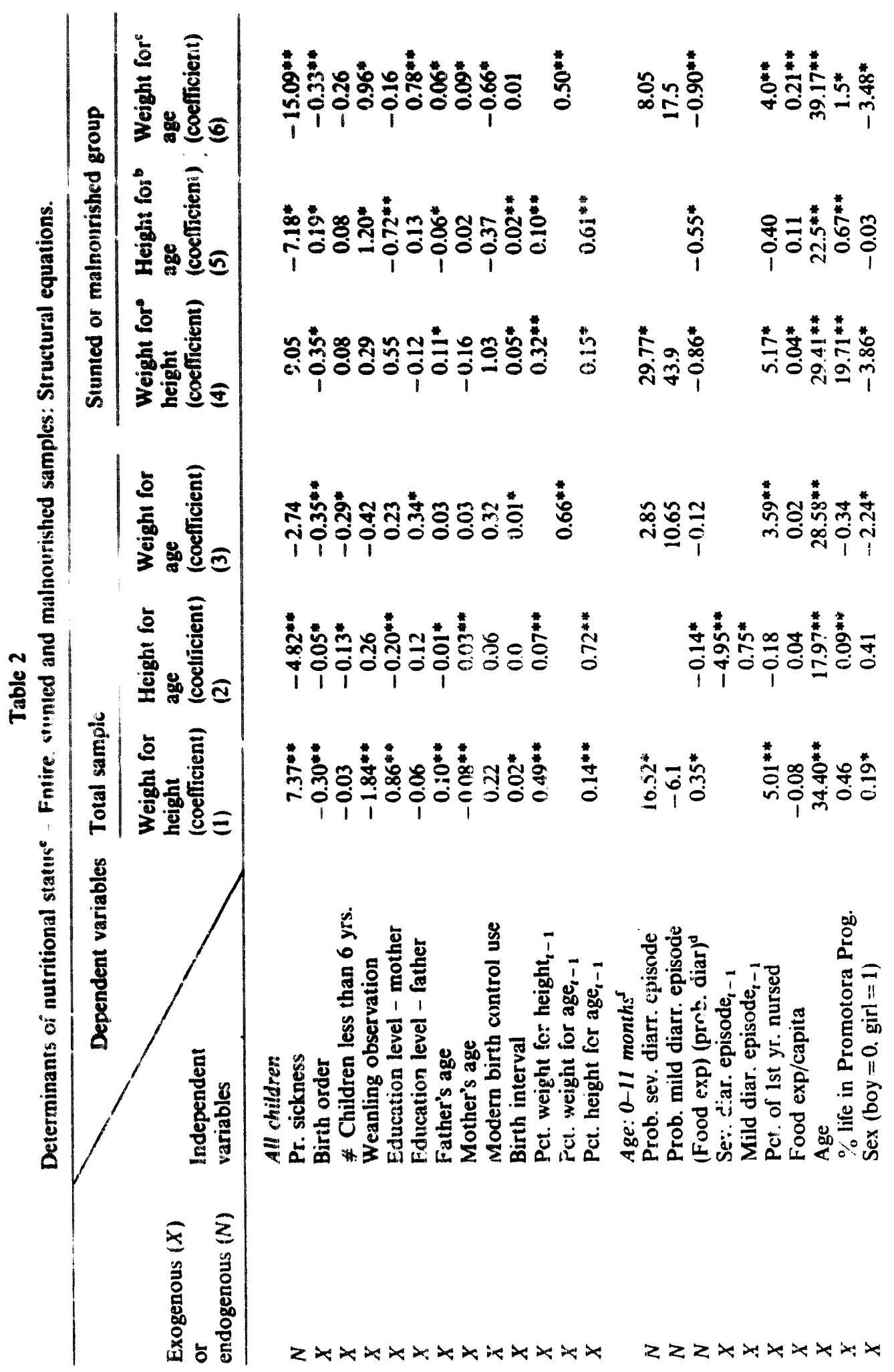




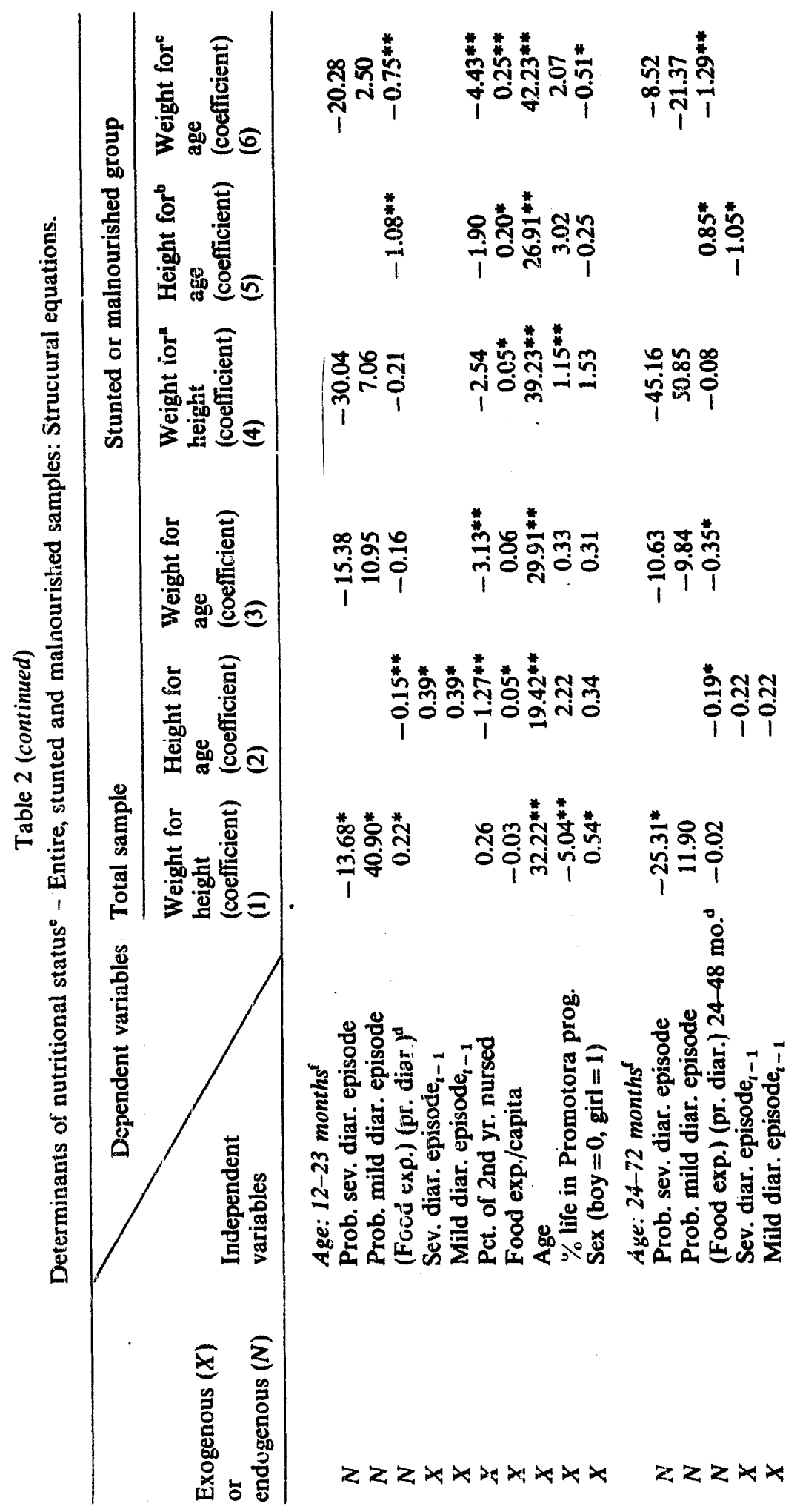




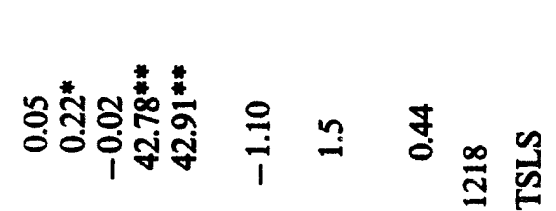

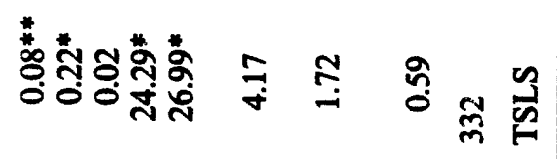

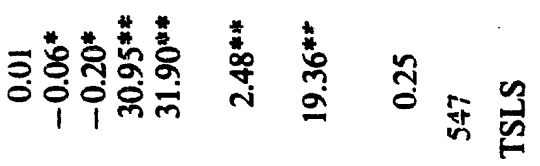

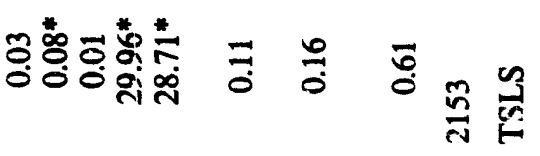

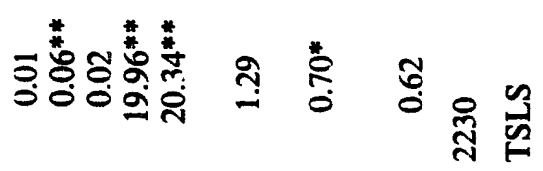

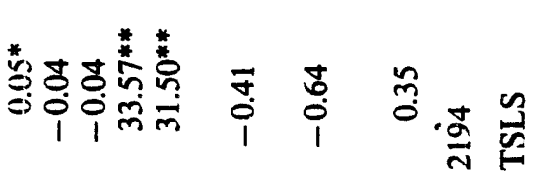

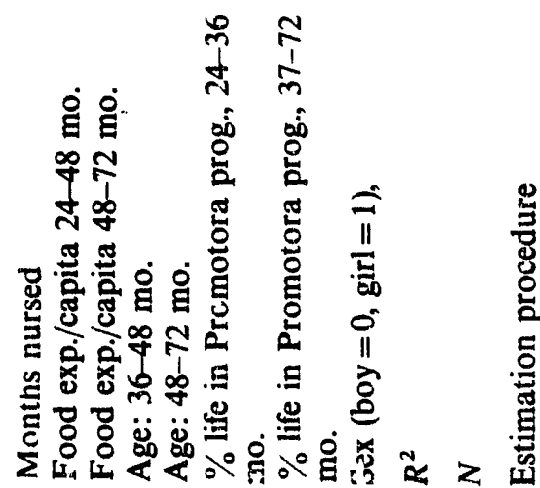

$x x x x x$

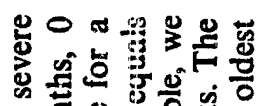

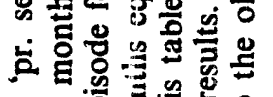

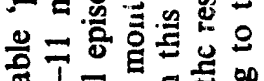

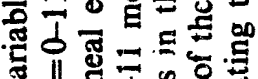

ช

证

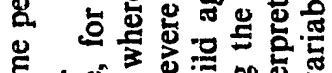

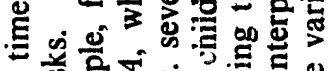

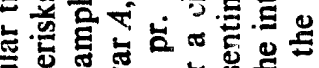

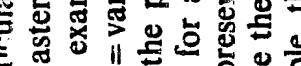

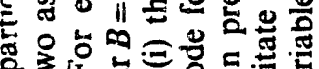

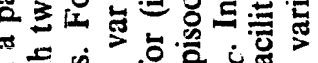

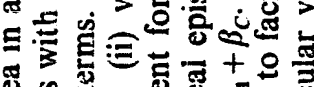

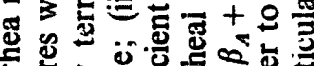

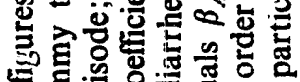

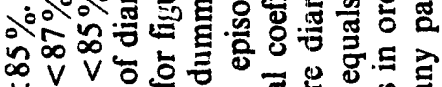
$\checkmark \vee V$ 可

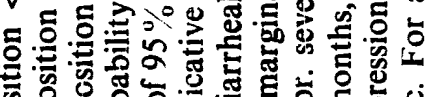

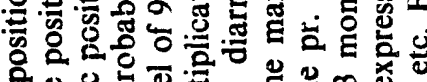

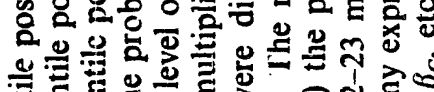

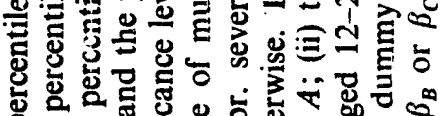

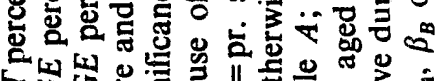

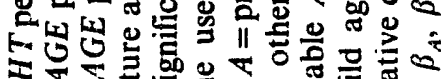

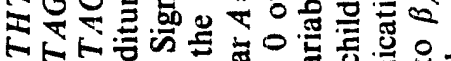

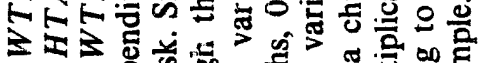

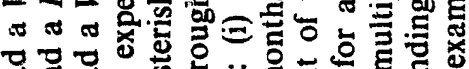

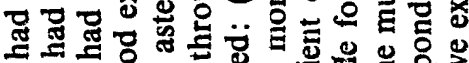
5 和

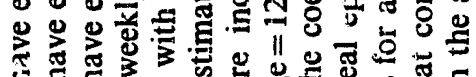
等

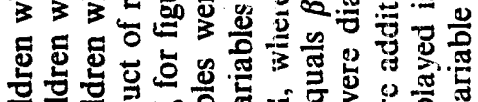

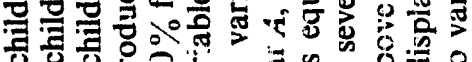

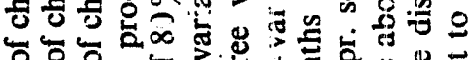

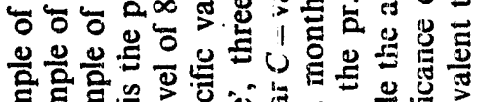

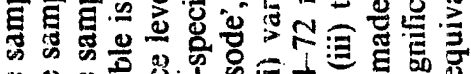
品。 …0.0.0. 贺:

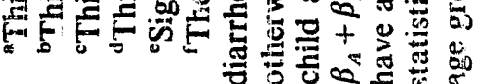




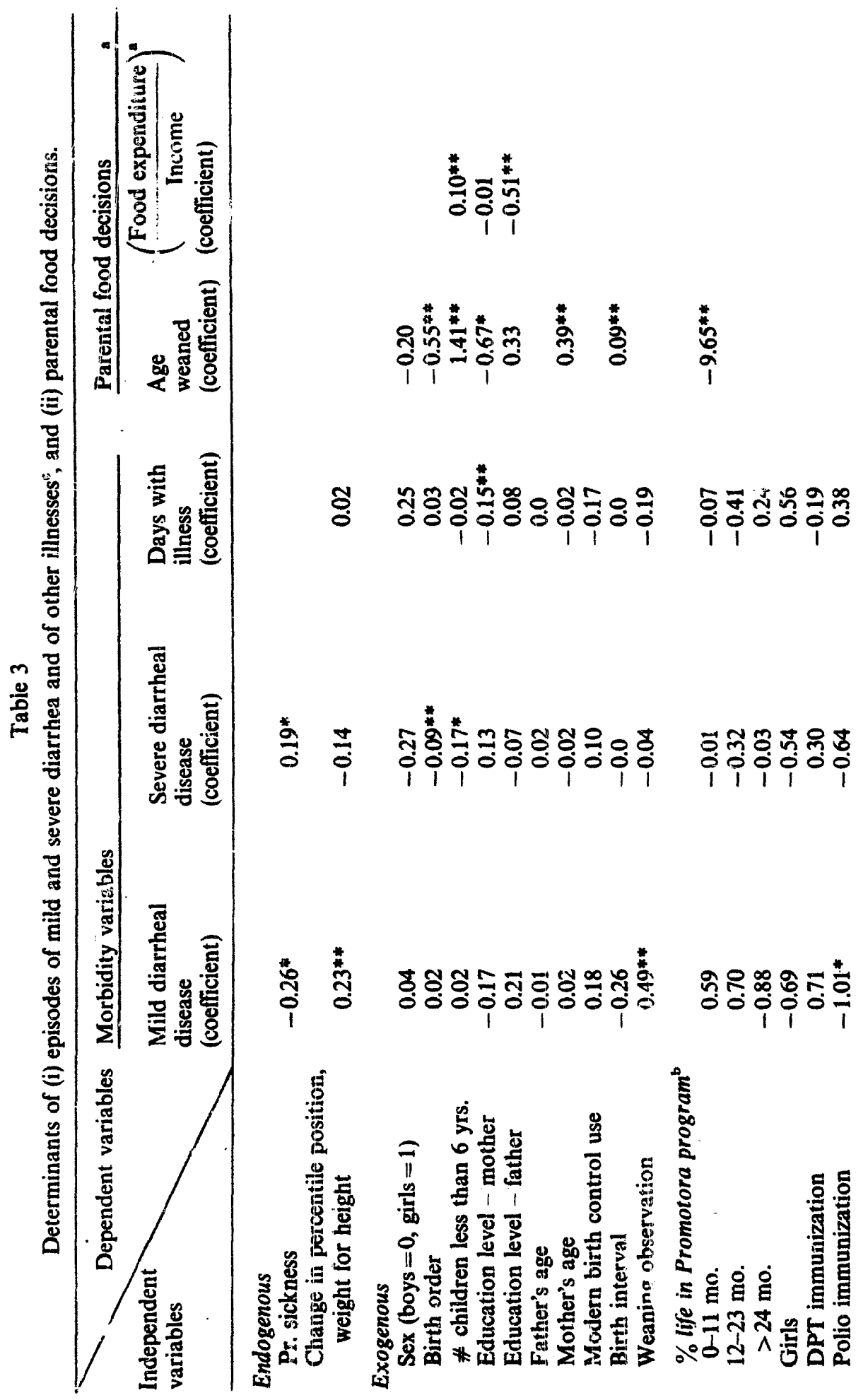


厗

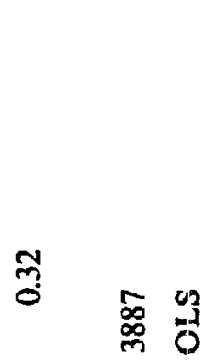

;

वั่

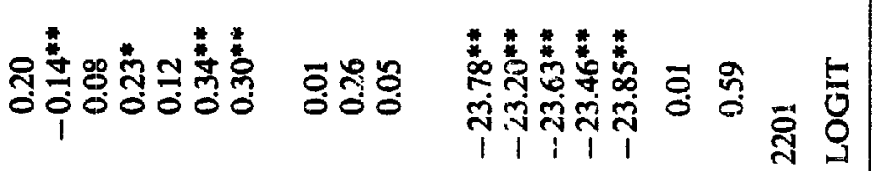

总

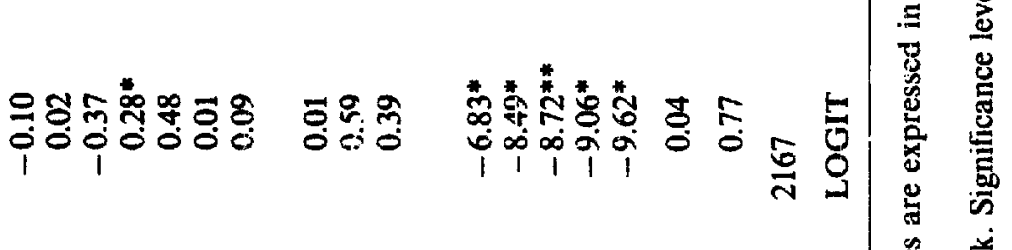

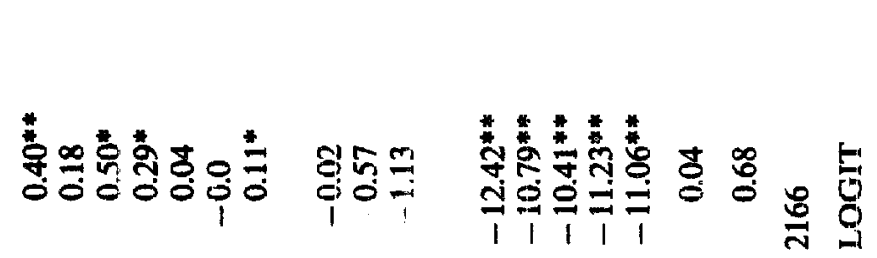

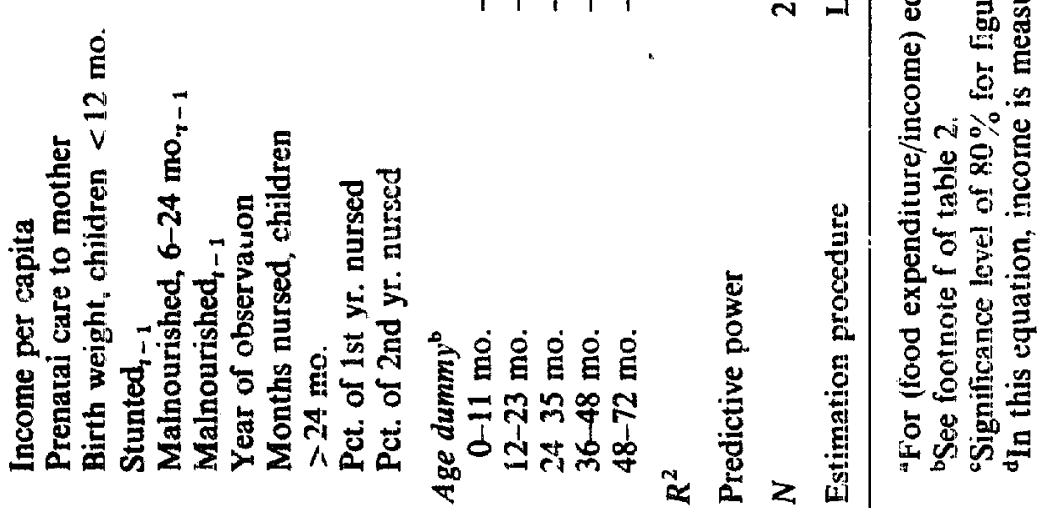


affected than its height. This is supported by the negligibte change in WTAGE score that is associated with severe diarrhea in the first year. With a slowing of growth, the $V T H T$ score rises. On the other hand, a mild diarrhea episode is of far less concern. Ir fact, children with mild diarrhea have a slightly higher $H T A G E$ score (by 0.75 points) and a lower WTHT score.

After the first year, a severe diarrheal episode is highly deleterious for a chiid's WTHT score, with a potential loss of 1 to 2 points. A mild diarrheal episode does not appear to lower a child's WTHT score significantly. Diarrhea is also of minor consequence for a child's $H T A G E$ score at this time (ever if one considers the indirect effect on HTAGE caused by the effect of a severe diarrheal episode on $W T H T$ ). These results tend to validate the econometric model as they are consistent with the results found in the literature on malnutrition.

Policies to reduce the likelihood of severe diarrhea would have a stronger impact on a nutritionally vulnerable child. Even more than with normal children, severe diarrhea after the first year will lower the acutely malnourished child's WTHT score by as much as 4.5 points [table 2, eq. (4)]. The effect of a past history of severe diarrhea is to redice a stunted child's HTAGE score by 1 point. As above, a mild diar hea episode is not clearly adverse to a child's nutritional status.

The most damaging effect of other illnesses is with respect to a child': long-term structural development, with a significant decline in $H T A G E$ score. The attendant rise in $W T H T$ score again suggests that in the event of illness, the body channels nutrients to the higher priority of maiataining body weight at the expense of normal structual development. Although the WTHT score rises, WTAGE score falls, though less than HTAGE.

Malnourished children are also at higher risk of further illness [table 3, eq. (3)]. For a child in the critical age of 6 to 24 months, a low WTHT score in the previous pericid raises the probability of a severe diarrhea episocle (table 3 , eq. (2)]. Similarly, stunted children are more susceptible to both mild and severe diarrheal episodes. Equaliy interesting, there is an inverse (direct) relationship between a change in $W T H T$ score and the protability of severe (mild) diarrhea. Since severe diarrhea is the principal determinant of a lowered WTHT score, the self-reinforcing effect of lowering diarrhea and improved nutritional status is clear from the results. Conversely, the emergence of $\operatorname{ar}_{\mathrm{i}}$ adverse nutritional status contributes to the likelihood of diarrhea. Low birthweight increases (reduces) the likelihood of severe (mild) diarrhea in the fir st year.

Finally, the coefficient of the nonlinear term $\left(F O O D^{*} P R . D I A R_{1}\right]_{t k}$ supports the argument that poor health not only directly weakens a child's nutritional status, but also raduces the efficiency of nutrient use. The variable's coefficient is negative in the $H T A G E$ equations, suggesting that diarthea reduces 
the coefficient of the food expenditure variable. In the WTHT equation, positive coefficients emerge in both the first and second years. This suggests that greater foud expenditure at this time may weaken the adverse effect of diarrhea by channelling nutrients to maintain body weight, at the expense of structural development. For children at risk of acute and chronic malnourishment, even this displacement is unsuccessiul. The negative coefficient $\left[F O O D^{*} P R . D I A R\right]_{t k}$ in both equations suggests the clominant negative effect of diarrhea on the impact of food expenditure.

Dynamics of nutritional change. First, it is important to note that a large proportion of the variance among children in nutritional status in the first seven months of life is not explained by our socioeconomic or health factors. In Heller-Drake (1976b), we attempted to explain the nutritional scores of children aged 1 to 7 months, and obtained an $R^{2}$ of no more than 0.05 . These equations did not include variables proxying a child's genetic inheritance (such as parental height or stature), and it is likely that such variables would explain much of this variation. Similarly, it is not surprising: that there is a positive correlation between the WTHT and HTAGE scores of a child in the current and previous periods. For the entire sample, $49 \%$ and $72 \%$ respectively, of the previous period's $W T H T$ and $H T A G E$ scores are carricd over to the current period. For the acutely malrourished group, the coefficient on $W T H T_{t-1}$ is significantly lower than for the entire sample: 0.32 relative to 0.50 (table 2 , eq. (4)). An acutely malnouristed child has far greater potential for variability in its $W T H T$ score.

Second, the results indicate that a child's HTAGE is positively correlated with its $W T H T$ in the previous period and vice versa. Thus, nutritional programs may promote improvements in WTHT score for their dynamic impact on structural development. This effect is greatest for the stunted group, with a coefficient of 0.10 relative to 0.07 [table \%, eqs. (2) and (5)].

Some evidence also emerges on the hypothesis of a 'natural' histery of a child's nutritional and health status. Examining the age dummy terms in the structural equations, no systematic pattern emerges across age grcups. From the statistical significance of the marginal dummiy terms (up to age 48 months), there may bs a slight increase in the $W T H T$ intercept in the fourth year (from 31.5 to 33.5), a slight rise in HTAGE score over time (from 18.0 in the first year to 19.4 in the second and 20.3 thereafter) and a peaking in $W T A G E$ in the third year.

The impact of nutrient sources. The relative impact of breast feeding and food expenditure clearly changes in the early years of a child's development. In the first year, a child that is breastfed over the entire year will emerge with a highly significant difference in its $W T H T$ score, elative to a child that has been weaned immediately. For example, for every rnonth breastfed in the 
first year, a child gains more than 0.4 points in its $W T H T$ score (up to the 5.01 points associated with breast feeding during the entire period) [table 2, eq. (1)]. Per capita food expenditure has a negative, though insignificant, impact during the first year. If a child were immediately weaned at birth and consumed the mean weekly food expenditure of 253 pesos for the sample, this would suggest a $W T H T$ percentile position 1.97 points lower. Frorn earlier estimates on the age group 1 to 7 months, the effect is strongest during this period [Heller-Drake (1976)], 7.65 points, and by inference, must dampen in order to yield a coefficient of 5.01 for the entire first year. On the other hand, a child's HTAGE score is insensitive to these alternative nutrient sources during the first year.

After the first year, breast feeding becomes significantly less important for a child's WTHT score and has a dampening effect on the child's HTAGE score (with a maximum loss of -1.26 points in $H T A G E$ for a child that has not been fully weaned by the end of its second year). The negative effect is more striking in terms of WTAGE (with a maximum potential loss of approximately -4.06 points). For older children (over 2 years), nursing has a long-term legacy of 0.05 points on the WTHT score for each month nursed.

Surprisingly, the level of family food expenditure per capita is not a critical factor in determining nutritional status variations, at least for the entire sample of children. Although the coefficient of $F O O D_{t k}$ in the HTAGE equation is statistically significant, even a level of food expenditure per capita one standard deviation above the average for the sample would yield no more than a 1.5 point difference in $H T A G E$ score. As expected, nutritional scores decline during the weaning period, but as implied above, only in terms of the WTHT score.

For an acutely mainourished child (low WTHT scores), the appropriate pattern of nutritional supplementation is clear from table 2. Breast feeding in the first year is at least as decisive as above. ${ }^{45}$ In the second year, weaning of a malnourished child becomes more imperative than for the entire sample, as the coefficient on breast feeding becomes sharply negative. The positive effect of food expenditure during this and subsequent periods is not large; a one siandard deviation change in weekly food expenditure (150 pesos) has no more than a 0.75 point impact in $W T H T$ score.

For a stunted child (low HTAGE score), the effect of breast feeding is not statistically significant until the second year and then only adversely. The negative coefficient on $H T A G E$ for this group is -1.90 relative to -1.27 for the entire sample [table 2, eqs. (2) and (5)]. $F O O D_{t k}$ is relatively more ${ }^{46}$

\footnotetext{
${ }^{45}$ Estimates of reduced form equations suggest that each additional month of nursing is worth 0.7 poirts (as compared with 0.53 for the entire sample) [Heller and Drake (1976)].

${ }^{46}$ The: reduced form coefficients suggest a potential net change half as large, but still this remains significant [Heller and Drake (1976)].
} 
decisive for the stunted group; in the second and third years, a one stanclard deviation increase in weekly food expenditure can raise the HT.4GE position as much as 3 points (relative to only approximately 0.45 for the entire sample).

Two additional points should be noted. The results do $\mathrm{n}$ )t suggest that food expenditure has no influence on a child's absolute weighi or height. For example, earlier results (not shown) suggest that food expenditure per capita in the first year has a small positive effect on weight and height. Breast feeding during the entire first year contributes half a centimeter to height. The results of table 2 capture changes relative to a norm. Second, the advantage of differentiating between WTHT and HTAGE emerges from the results. Eq. (3) of table 2 suggests that breast feeding in the second year lowers WTAGE whereas the results of eqs. (1) and (2) in table 2 indicate that this occurs only because it causes stunting, not because the chiid's WTHT score is adversely affected. For the same reason, the WTAGE variable obscures the contribution of iood to height as opposed to weight.

Finally, is a child's health status aficoted by whether it is breastfed or at the time of weaning? A child that is breastfed through the second year has a significantly lower likelihood of mild diarrhea [table 3, eq. (1)]. This may simply reflect that delayed weaning postpones exposure to food-horne illnesses. ${ }^{47}$ The weaning period is clearly a period of increased sensitivity to diarrhea, though not to other illnesses.

Promotora program. The results suggest that the principal impect of the Promotora program was on long-term nutritional status (HTAGE), with the strongest impact on children in their second year of life. The impact of a high proportion of a child's life in the Promotora program on its HTAGE score is only 0.09 points for a one-year old compared with $2.2,1.2$ and 0.7 for children in the next three years, respectively. The short-term effect on $W T H T$ or WTAGE is generally insiginificant; when it is significant, it is clearly negative. Again this may reflect the program's impact on the child's height relative to its weight, thus leading to an increase in $H T A G E$ and a corresponding decrease in $W T H T$ position as a consequence. No significant change is observed from WTAGE in the sample considered. ${ }^{48}$

\footnotetext{
${ }^{37}$ This is also borne out by the difference in mean probability of diarrhea according 0 whether a child is breastfed. In the first two years of life the probability of mild and severe diarrhea while nursed is 0.072 and 0064 , respestively; for a child that is weined, these probabilitie: are 0.09 and 0.10 , respectively. These are monthly probabilities of diarrhea.

${ }^{48}$ There are three possible explanations for the ambiguity of the results concurning the Promotora program's impact. First, we were forcec to omit data on the first two years of the program because height data were not collected. Much of the relevant change in nutritional status inspired by the program may have occurred during that period. Second, our variables controlled for the percentage of a chitäs life spent in the program, not the amount of time the family was enrolled. The latter may have been the more relevant variable. Third the Fromotora prograrı placed considerable stress on reaching out to families with nutritional and health
} 
In terms of health, participation in the Promotora programs lowers the likelihood of diarrhea in the first and third years of life, but raises it during the second. It has liitle effect on the probability of other illnesses. It was also hypothesized that over time, general improvernents in the sanitary situation may have occurred. This is possible, but it is not captured by a calendar year term, which is clearly positive for the level of risk to both kinds of diarrhea.

Medical programs. Our results indicate that exposure to and utilization of health services is of nixed value in reducing the risk of illness. Families that use modern contraceptive techniques or receive prenatal care have a slightly (though not significantly) higher risk to diarrhea. While children with polio immunizations have a lower probability of both kinds of diarrhea, those that have receiver a DFT immunization are at higher risk. A child with both inmunizations is at lower risk. Use of health services, receipt of prena:al care by the mother, and use of modern birth control methods all reduce the probability of other illnesses. The policy implications of these results should not be overstated, since we could only weakly measure the quality and quantity of health services consumed by the family.

\subsection{Economic constraints and farnily decisions affecting nutritional and health status}

Parental income. ${ }^{49}$ Our model suggests family income influences a child's nutritional status through its effect on nutrient intake, and health status through the purchase of goods and services. As might be expected, food expenditure rises less rapidly than income, with an income elasticity $\left(i+\beta_{\text {INCOME }}\right)$ of 0.50 [table 3 , eq. (5)]. Thus, substantial leakage would arise in any income supplementation scheme in terms of its impact on family rood expenditure, even before one considers its division within the family. Less obvious, but equally important, the age of weaning is acceleruted as inconin: rises. This may reflect the effect of a higher opportunity cost of the mother's time and/or that breast milk may be considered an 'inferior' good. Every additional thousand pesos of monthly income would reduce the nutsing period by 1.3 months.

The net effect of income on nutritional status, as estimated from the reduced form equations (not shown), ${ }^{30}$ is positive, but quantitatively small. For the entire sample, a thousand peso increase in income raises $H \mathrm{I} A G E$ and $W T A G E$ scores by 0.3 and 0.9 points, respectiveiy. Increased income has little discernable effect on children already stunted, though it has an input on

problems and it is possible that a negative correlation between program participation and nutritional status may reflect this.

${ }^{49}$ Mean real monthly per capita inc sme is 1253 pesos, with a standard deviation of 971 pesos.

${ }^{50}$ Heller and Drake (1976, p. 27). 
children at risic of low WTHT scores (with an income elasticity on WTHT score of $1.4 \%$ ).

Finally, by allowing greater parentally provided inputs higher income significantly reduces the child's probability of mild diarrhea, with an elasticity of 0.47 . On the other hand, it raises the probability of other illnesses, but at a lower level of sig:ificance $(t=1.23)$ and elasticity $(0.188)$.

Competition $f(r$ family resources. The results indicate that child competition adversely affecis nutritional status, though not health status. First, nutrient intake per child falls. Although the level of family food expenditure rises with the number of young children, the elasticity is low: 0.10 . Whether for physiological or economic reasons, the age of weaning is also accelerated by 1.4 months for each additional child under age 6 in the family. Second, the greater the number of competing children under age 6 , the lower the $H T A \cup E$ score [table 2, eqs. (1) to (3)]. Family planning programs aimed at wider spacing between a child and an earlier sibling may both lead to a lonser period of breisit feeding ${ }^{51}$ and may raise $W T H T$ and $W T A G E$ scores, though the maximum differential is only 1 point. ${ }^{52}$ Shorter intervals have a differentially worse impact on the nutritional status of both malnourished and stunted children. Each additional month's interval between a child and its predecessor raises the former's WTH'T position by 0.045 points and HTAGE by 0.024 points. Both effects are larger than for the entire child population sample.

Parental discrimination across children. Ciur hypothesis that higher birth order childre: are discriminated against ic unfirmed. The highest hirth order child in the sainple - nine - wil! be approximately 3 percentile points worse off than the first baby in a family for $W T H T$ and $W T A G E$ and 0.5 points lower in HTAGE. Although it is possible this siri ly reflects the physiological consequences of being of higher bit th order, it is interesting that this differential only emerges in the latter half of the first year. ${ }^{53}$ This lends support to the cause not heing a lower weight now-born, but rather intrafamilial discrimination. Lat $*$ r parity children will also receive one-half month less nursing than the preceding child [table 3, eq. (4)]. This is after correction for the effect of the age of mother on nursing. ${ }^{54}$

Our results are not conclusive on whether there is a bias against baby girls or not. Despite the fact that the anthropometric standards are sex-specific;

\footnotetext{
${ }^{51}$ This may arise if there were a high correlation between the length of nursing of a given crild and its predecessor.

${ }^{52}$ This has been suggested in an earlier paper by W/ray and Aguirre (1969).

\$3 In the sample of children aged 0-6 months, birth order has no effect on nutritional status. Heller and Drake (1976, p. 25).

${ }^{54}$ Surprisingly, the age of the mother s positively correlated with the period of nursing. This may reflect some collinearity between the educational level and age of mother in the sample.
} 
girls are cleariy lower in $W T A G E$ [table 2, eq. (3)] by as much as 2 to 3 points at the end of the first year of life, with the differential narrowing thereafter to $1.2-1.7$ points. ${ }^{55}$ In the first year this reflects a slightly higher HTAGE position and a lower $W T H T$ position; thereafter, possibly after wearing, their HTAGE positions are lower though these results are not significant. In an earlier estimation, we indirectly tested the hypothesis of discrimination against girls in the allocation of a given level of family food expenditure, but could not find supporting evidence. ${ }^{56,57}$

Parental discrimination does not appear to be present as a factor influencing the probability of illiess. The sex of child is not a statistically signifeant factor in determining its health status. As for birth order, the resul:s inclicate that earlier children are more at risk, though this result is significant only for severe diarrhea episodes.

Parental quality. The caus? relstion berween parental quality and nutritional o: health status is not clear from the results. First, more e Jucated parents ${ }^{58}$ do not spend more on food for their family, ceteris paribus. Not surprisingly, maternal educaticn is negatively correlated with the length of nursing. Women with secondary education will nurse almost 3.5 months less than an uneducated woman. Second, to the extent that more parental education bas a statistically significant impact, it biases a child toward a high $W^{T} H^{T}$-low $H T A G E$ position. Children of educated mothers appear to have higher $W T H T$ and lower HTAGE scores. Third, greater maternal education lowers the likelihood of mild diarrhea and of other illnesses but increases it for severt: diarrhea (although the former effects are significant at a higher confidence level); paternal education operates in a completely opposite way. Fourth, rhildren of older muthers and young fathers appear high in their HTAGE score, low in WTHT, have the highest probability of mild diarrhea but the lowest probability of severe diarrhea. This may reflect the optimal combination of maternai child-rearing experience and paternal energy for income-earning in plantation agriculture.

In general, education and age together account for a maximum variation of 3.5 points for any child. Since the causal mechanisms involved are not easily identinied, the policy implications must be considered as vague. However, the results may serve as clinically useful rules of thumb for

\footnotetext{
${ }^{55}$ This ris from the reduced form equations [Heller-Drake (1976)].

${ }^{56}$ In a c arlier study using the Gomez standard for WTAGE, Drake and Fajardo $(1969$, p. 15) note $a$ dian atic decrease in the female relative to male malnourishment rate

${ }^{57}$ In e, 16$)$ and $(8)$ we tested whether a given level of family food expenditure per capita had a difierentially greater impact on the nutritional status of boys relative to girls. No significant differenc: ir the effect of food emerged.

${ }^{58}$ In w sample, mothers and fathers received so more than 6 and 9 years of education, respectively.
} 
evaluating the risks of diarrheal disease or of malnourishment in maternalchild health programs.

\section{Conclusion}

This paper has attempted to model the process of autritional change and the development of risk of childhood morbidity. Since both processes are highly complex, the data subject to considerable imprecision, and the methodological problems of estimating such a model great, the ambiguity of sonie or our results is not surprising. In fact, the clarity of many of the results is itself unusual given these problems. However, the following insights are of sufficient heuristic value such as to warrant further policy analysis in order to ve:ify the accuracy of these estimates.

(i) The character of nutrient intake in the first two years of life is pivotal. Insufficient breast feeding in the first year sharply lowers the child's current $W T H T$ score, with an equally serious dynamic impact on its $H T A G E$ score. In fact, breast feeding is one of the principal diffe;entiating factors across children in their first seven months. These effects are even stronger for malnourished infants. The beneficial effects of breast feeding clearly taper off near the end of the first year and ac ually become deleterious to the child's HTAGE beyond this point. The average period of breast seeding is 9-11 months within the sample. This suggests that family characteristics which imply significantly lower or higher periods of breast feeding ought to cal. forth further maternai-cinild health erlu sation. Surprisingly, the level of food expenditure does not exert a significant impact on nutritional status, except in the sense that if a. child is not weaned by the end of the first year, his nutritional status will decline.

(ii) Our model affirms the importance of differentiating between a child's WTHT and HTAGE. A WTAGE measure blurs the character of nutritional development, since it is the composite of the former two measures. Policies aimed at raising a child's $H T A G E$ nay not be the same as those designed to influence $W T H T$. In the past, ecc nomists have failed to incorporate this distinction into their analyses of the social costs of malnutrition. If these costs were to arise principally fron a low position on only one of these measures (for example, $W T H T$ ), policies that focussed on raising the WTAGE measure would not necessarily be cost-effective.

(iii) Our results confirm the interclependence of poo: nutritional status and poor health. Episodes of severe diarthea clearly worsen a child's nutritional status, particularly in the first two years. Other kinds of illnesses contribute to the 'stunting' of a child. For ch ildren who are either stunted or acutely 
malnourished, diarrhea sharply weakens whatever positive impact food expenditure has on nutritional status. Conversely, children who are mainour. ished are at greater risk to severe diarrhea and to other illnesses. Althour: our results do not yield any clear policy remedies for lowering $t^{1} l e$ risk of severe diarrhea, they do suggest the importance of minimizing the adverse nutritional inpact of such illnesses, once they have occurred.

(iv) Although our specification of the health status model includes a substantial number of potentially relevant variables, our understanding of the factors that contribute to a diarrhea episode's occurrence remain limited $\left(r^{2}\right.$ $=0.02-0.03$ ). This may arise for several reasons. Since our data only captures episodes that occurred in the previsus month, and recall error for another person is also likely, it is possible that much of the diarrhea experienced by the population is missed, and this adds to the potential error involved. Absence of measures of environmental quality also must contributa to the low explanatory power. Another possible explanation is that the observed diarrheal rate in Cardelaria is relatively low - $14 \%$ - compared to many other Latin American communities of comparable socioecoso nic status, perhaps due to the environmental improvements that preceded the onset of th: Promotora program. Perhaps the range of experience captured by both our dependent and explanatory variables is too limited to fully measure the impact of the latter. Though some of the residual cases are still explained by sosioeco tomic factors, the majority of episodes are random occurrences that are nornal in any child's development. Thus, our results may not be extremely useful for measuring the impact of policies for communities where diarrhea is more endemic.

(v) The model docs provide support for viewing malnutrition and poor hedth as the consequence of family decision processes. The level and quality of nutrient intake are clearly affected by parental income and education. The results support the hypothesis that both child competition and parental discrimination adversely influence nutritional status. This suggest that an additional berielit from family planning programs would be an imf rovement in the nutritional status of children.

\section{References}

Butz, William P., Nutrition and health effects on fertility: Hypotheses, evide we and interventions on less developed countries, Unpublished paper, 2/75.

Cravioto, J., 197., The effects of malnutrition on the individual, in: A. Berg et a ... Nutrition, national development and planning (MIT Press, Cancoridge, MA).

Cravioto, J., 1975, Microenvironmental factors in severe protein-calorie malnutrition, in: $\mathbf{N}$. Scrimshaw ard M. Behar, eds., Nutrition and agricultural development (Plenum, ?New York).

Drake, William D. and L.F. Fajardo, 1976, The Promotora prograrn in Cindelaria: A Colombian attempt to conirol malnutrition and disease, 1968-1974, Juñe 25 Community Systems Foundations, Cali, Colombia). 
DuMousche!, William, n.d.. The regression of the dichotomous dependent variable, Unp blished paper (University of Michigan, East Lansing, MI).

Durbin, J.. 1970, Testing for serial correlation, in least squares regression when some of the regressors are lagged dependent variables, Econometrica 38, 410-421.

Garn, Stanley, 1976, The anthropometric assessment of nutritional status, in IV.A.H. Smith, ed., Proceedings of 3rd National Nutrition Workshop for Nutritionists from University Affiliated Facilities, April (Memphis, TN).

Grossman, Michael, 1972, The demand for health (National Bureau of Economic Research, New York).

Habicht, J.P. et al., 1974, Height and weight standards for preschool children, The Lancet, April $6,614$.

Heller, P., 1976, Interactions of childhood mortality and fertility in W. Malaysia, 1947-1970, Discussion Paper no. 57 (Center for Research on Economic Development, University of Michigan, Ann Arbor, MI).

Heller, P. and W. Drake, Malnutrition, child morbidity and the family decision process, Discussion Paper no. 58 (Center for Research on Economic Development, University of Michigan, Ann Arbor, Mi).

Kmenta, Jan, 1971, Elements of econometrics (MacMillan, New York).

Martorell, R. et al., 1975, Acute morbidity and physical growth in rural Guatemalan children, American Journal of Diseases in Children 129, no. 1, 1296-1303.

Martorell, R. et al., 1976, Diarrheal diseases and growth retardation in preschool Guatemalan children, American Journal of Physical Anthropology 43, 341-346.

Morley, D., 1973, Paediatric priorities in the developing world (Butterworth, London).

National Academy of Sciences, 1973, The relationship of nutrition to brain development and behavior, June (Washington, DC).

National Center for Health Statistics, 1976, NCHS growth charts, 1976, Monthly Vital Statistics Report 25, no. 3, suppl.

Owen, G.N., 1973, The assessment and recording of measurements of growth of children: Report of a small conference, Pediatrics 51, no. 3, 461-466.

Owen, G.N. et al., 1974, A study of nutritional status of preschool children in the United States. 1968-1970, Pediatrics 53, no. 4, part II, suppl., 597-646.

Pradi!n, A M.D., 1273, Nutritional effects of a simplified health system in a semi-urban community, Rockefeller Foundation Report for Grant 65071, Annex I, Dec.

Robson, John R.K., 1972, Malnutrition: Its causation and control (Gordon and Breach, New York).

Scrimshaw, N., C.E. Taylor and J.E. Gordon, 1968, Interactions of nutrition and infection, World Health Organization, Monograph no. 57.

Swlowsky, Marcelo and S. Reutlinger, 1975, Undernutrition and poverty, IBRD Staff Working Paper no. 202, April.

Tanner, 1966, Standards from birth to maturity for height, weight, height velocity and weight velocity: British children, 1965, Arch. Dis. Childhood 41, 454-471, 613-635.

Waterlow, J.C., 1973, Note on the assessment and classification of protein energy malnutrition in children, The Lancet, July 14, 87-89.

Waterlow, J.C., 1974, Some aspects of childhood malnutrition as a public health problem, British Medical Journal, Oct. 12, 88-90.

Welch, F., Chance, child traits and choice of family size, Frand Memo.

Welch, F., 1974, Sex of children: Prior uncertainty and subsequent fertility behavior, Rand R1510RF, Aug.

Willis, R., 1973, Economic theory of fertility behavior, Journal of Political Economy 81, no. 2, 238-278.

Woodward, W.E. et al., 1973, Acute diarrhea on an Apache Indian reservation, American Journal of Epidemiology 99, 281.

Wray, Joei D. and Alfitedo Aguirre, 1969, Protein-calorie malnutrition in Candelaria Colombia, I. Prevalence: Social and demographic causal factors, Journal of Tropical Pediatrics 15, no. 3, 76-95.

Zerfas, A.J., 1975, Selected indicators of nutritional states obtained by 4 rect examination, WHO technical paper, NUT/EC/75.18, Oct. 